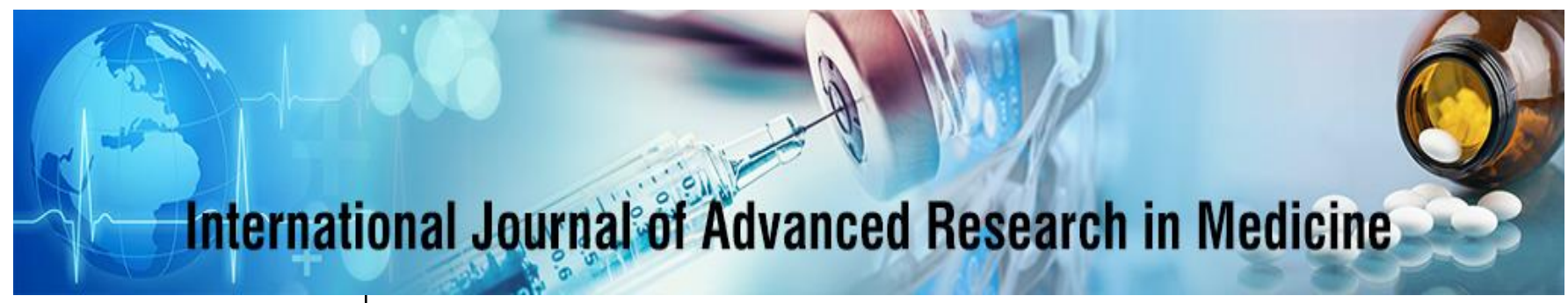

E-ISSN: 2706-9575

P-ISSN: 2706-9567

IJARM 2020; 2(1): 29-36

Received: 23-01-2020

Accepted: 25-02-2020

\section{Dr. Sumeera Banday}

Assistant Professor,

Department of Respiratory

Medicine Hamdard Institute of

Medical Sciences and Research,

Hamdard Nagar, Delhi, India

\section{Dr. MB Gupta}

Professor, Department of

Respiratory Medicine, School

of Medical Sciences and

Research, Sharda University,

Knowledge Park III, Greater

Noida, Uttar Pradesh, India

Corresponding Author:

Dr. MB Gupta

Professor, Department of

Respiratory Medicine, School

of Medical Sciences and

Research, Sharda University,

Knowledge Park III, Greater

Noida, Uttar Pradesh, India

\title{
A cross sectional study of Metabolic Syndrome in patients with COPD
}

\section{Dr. Sumeera Banday and Dr. MB Gupta}

DOI: https://doi.org/10.22271/27069567.2020.v2.i1a.36

\begin{abstract}
Background: The term "metabolic syndrome" is given to the condition in which there is a coexistence of a constellation of interrelated factors that increase the risk for development of diabetes mellitus, nonfatal and fatal cardiovascular disease as well as all cause mortality. Patients with COPD may be at an increased risk of development of MetS due to limitation to physical activity imposed by respiratory symptoms.

Methods: A cross sectional study was designed to study the prevalence of metabolic syndrome in 100 patients with COPD (Indian Guidelines). The characteristics of the metabolic syndrome were measured and conclusions were drawn regarding presence of metabolic syndrome as per the International Diabetic Federation Guidelines (2005).

Results: Out of total number of 100 patients of COPD, 28 satisfied the criteria of metabolic syndrome. This constitutes $28 \%$. The mean age of patients with metabolic syndrome was 61years. Male to female ratio was about $2: 1$. The number of smokers with metabolic syndrome was almost double that of nonsmokers. The smoking index of patients with metabolic syndrome was 212 on an average. The most common metabolic abnormality found was raised fasting blood sugar (average FBS level was 106 $\mathrm{mg} \%$ ). The mean waist circumference was $93 \mathrm{~cm}$, mean triglyceride level was $153 \mathrm{mg} \%$, mean HDL level was $44 \mathrm{mg} \%$, mean systolic and diastolic blood pressure was 147 and $89 \mathrm{~mm} \mathrm{Hg}$ respectively. Within the various COPD groups (Indian guidelines), all the patients with Severe COPD had metabolic syndrome, but none of the patients with Mild COPD had metabolic syndrome.

Conclusions: This study revealed a high prevalence of metabolic syndrome in the north Indian population suffering from COPD particularly those having more severe grade of COPD. During the period of the study there was no fatal event in the study group. All the patients were put on appropriate treatment after enrollment in the study and were doing well till last follow up
\end{abstract}

Keywords: metabolic syndrome (MetS), COPD

\section{Introduction}

The metabolic syndrome (MetS) represents a cluster of risk factors that increases the risk for developing diabetes mellitus ${ }^{[1]}$, cardiovascular disease ${ }^{[2]}$, as well as mortality ${ }^{[3]}$. MetS is characterized by the presence of abdominal obesity, atherogenic dyslipidemia (elevated triglyceride levels, increased low-density lipoprotein [LDL] particles, low high-density lipoprotein cholesterol [HDL-C] levels), raised blood pressure, insulin resistance (with and without glucose intolerance) and prothrombotic and inflammatory states ${ }^{[4]}$. It predicts the development of type II diabetes mellitus and cardiovascular disease. The syndrome has been given several names including the "metabolic syndrome", the "insulin resistance syndrome", the "plurimetabolic syndrome", and the "deadly quartet" ${ }^{[5-8]}$.

The mechanisms underlying the MetS are not fully known, however resistance to insulin stimulated glucose uptake seems to modify biochemical responses in a way that predisposes to metabolic risk factor. A central role has been attributed to the proinflammatory cytokines, Tumor necrosis factor (TNF- $\alpha$ ) and interleukin (IL-6). TNF- $\alpha$ impairs insulin-stimulated glucose uptake in a variety of cells and decreases lipoprotein lipase activity. Both cytokines increase hepatic lipogenesis and elicit a systemic acute-phase response. C-reactive protein (CRP) shows a strong independent association with the risk of coronary heart disease and other atherothrombotic events. CRP levels have also been found to correlate with Body Mass Index (BMI) and some features of the MetS ${ }^{[9,10]}$. Over a period of time various definitions of MetS have been given to help standardize the diagnosis of this syndrome like WHO definition, NCEP definition and international diabetes federation (IDF) consensus definition ${ }^{[11]}$. Chronic diseases are known to develop together ${ }^{[12,13,14]}$. 
COPD is associated with chronic heart failure ${ }^{[15]}$ and osteoporosis, independently from treatment with steroids and/or decreased physical activity ${ }^{[16]}$. In a study by Marquis et al. almost $50 \%$ of the patients with COPD had one or more components of MetS ${ }^{[17]}$. Conversely chronic heart failure is associated with hypertension and coronary or peripheral artery disease, diabetes mellitus and anemia. Type 2 diabetes is linked to hypertension and cardiovascular diseases ${ }^{[18]}$. Systemic inflammation has been proposed to be the commonest mechanism that leads to chronic diseases.

In patients with chronic diseases such as chronic obstructive pulmonary disease (COPD), unrelated disorders are relatively underdiagnosed ${ }^{[19]}$. Patients with COPD are at a 2 to 3 fold increased risk of cardiovascular disease, however the mechanisms responsible for this association remain largely unknown ${ }^{[20]}$. Several large prospective studies have shown that lung function impairment was predictive of increased cardiovascular morbidity and mortality, independent of smoking ${ }^{[21]}$. Positive associations with lung function impairment have been reported for major cardiovascular risk factors such as hypertension ${ }^{[22]}$, type 2 diabetes mellitus ${ }^{[23]}$, low-density lipoprotein cholesterol ${ }^{[24]}$ and overall obesity ${ }^{[25]}$. Impaired lung function has also been shown to be predictive of atherosclerosis [26] but the mechanisms underlying the relationship between impaired lung function and cardiovascular risk are unclear. MetS or specific combinations of its components, may play a key role in this relationship ${ }^{[27]}$.

COPD is primarily characterized by airflow limitation resulting from airway inflammation and remodeling that is often associated with parenchymal destruction and the development of emphysema. In some patients the disease is associated with systemic manifestations that can effectively result in impaired functional capacity, worsening dyspnea, reduced health-related quality of life and increased mortality ${ }^{[28]}$. Thus COPD is no longer a disease of lungs alone as it is often associated with a wide variety of systemic consequence. One of the most accepted hypotheses for systemic inflammation in COPD is that the inflammatory process that occurs in lung parenchyma 'spills over' into the systemic circulation and/or leads to priming and activation of different inflammatory cells ${ }^{[29]}$. Tissue hypoxia may be an important mechanism leading to inflammation in patients with COPD ${ }^{[30]}$. Physical exercise increases TNF- $\alpha$ levels in COPD patients that could lead to muscle wasting by different mechanisms like direct stimulation of protein loss, apoptosis of muscle cells and oxidative stress induced alteration in $\mathrm{TNF}-\alpha / \mathrm{NF}-\kappa \beta$ ratio ${ }^{[31-33]}$. Some co-morbid conditions are an indirect consequence of COPD and arise independently but are more likely to occur when COPD is present (i.e. ischaemic heart disease, lung carcinoma and osteoporosis). Others co exist because they become prevalent as part of ageing process such as diabetes mellitus or due to smoking or other exposure ${ }^{[28]}$.

According to the Indian guidelines following stages of COPD have been defined based on spirometry; At risk, Normal spirometry with chronic symptoms, Mild, $\mathrm{FEV}_{1} / \mathrm{FVC}<70 \%$ and $\mathrm{FEV}_{1}>80 \%$ predicted Moderate, $\mathrm{FEV}_{1} / \mathrm{FVC}<70 \%$ and $\mathrm{FEV}_{1} 30-80 \%$ predicted Severe, $\mathrm{FEV}_{1} / \mathrm{FVC}<70 \%$ and $\mathrm{FEV}_{1}<30 \%$ predicted ${ }^{[34]}$.

In view of increasing incidence of MetS in the general population and the impact of MetS on mortality and morbidity combined with the lack of clinical data from India, there is a need to do a comprehensive study to evaluate the presence of MetS in the Indian population in general and in patients with COPD in particular.

\section{Material and Methods}

The present study was a cross sectional study conducted on the patients attending the OPD of Department of Respiratory Medicine Santosh Medical College Ghaziabad Uttar Pradesh between August 2010 and October 2012 after approval by the institutional ethical board. Written informed consent was obtained from each participant after explaining the objectives and procedures of the study. 100 patients of COPD were selected after applying the inclusion and exclusion criteria of the study. Patients fulfilling the following criteria were included in the study

A. History of dyspnea, chronic cough or sputum production, and or history of exposure to risk factors i.e. smoking, occupational exposure, air pollution.

B. The patients were labeled as a case of COPD on the basis of spirometry. The presence of a post bronchodilator Forced Expiratory Volume in one second $\left(\mathrm{FEV}_{1}\right) /$ Forced Vital Capacity $(\mathrm{FVC})<70 \%$ and $\mathrm{FEV}_{1}>80 \%$ predicted confirms the presence of airflow limitation that is not fully reversible. Based on spirometric evaluation patients were further classified into at risk, mild, moderate and severe groups in accordance with Indian Guidelines of COPD ${ }^{[34]}$.

Patients with respiratory tract infection in preceding six weeks, patients having congenital or organic heart diseases, cardiovascular disease, pregnant females, chest X-ray showing any demonstrable bulla parenchymal scars, cavity, mass, patients having tuberculosis, liver disease or neuromuscular disorders were excluded from the study.

\section{Parameters studied}

1. Spiro metric evaluation of all participants by Medspiror spirometer was done. The presence of a post bronchodilator Forced Expiratory Volume in one second $\left(\mathrm{FEV}_{1}\right) /$ Forced Vital Capacity (FVC) $<70 \%$ and $\mathrm{FEV}_{1}>80 \%$ predicted confirms the presence of airflow limitation that is not fully reversible. Based on spirometric evaluation patients were further classified into At risk, Mild, $\mathrm{FEV}_{1} / \mathrm{FVC}<70 \%$ and $\mathrm{FEV}_{1}>80 \%$ predicted Moderate, $\mathrm{FEV}_{1} / \mathrm{FVC}<70 \%$ and $\mathrm{FEV}_{1} 30-80 \%$ predicted Severe, $\mathrm{FEV}_{1} / \mathrm{FVC}<70 \%$ and $\mathrm{FEV}_{1}<30 \%$ predicted ${ }^{[34]}$.

2. Anthropometric measurements Body weight and height were measured to nearest to $500 \mathrm{gms}$ and one $\mathrm{cm}$ respectively were observed by single observer ${ }^{[106]}$. BMI was calculated based on formula $\mathrm{BMI}=$ weight $(\mathrm{kg}) / \mathrm{height}$ $(\mathrm{m})^{2}$. Waist circumference was measured at midpoint between lowest rib and the iliac crest with an inelastic measuring tape. Waist circumference (WC) of $>90 \mathrm{~cm}$ in men and $>80 \mathrm{~cm}$ in women were taken as marker of central obesity. Data was analyzed according to International Diabetic Federation Consensus definition (2005) of MetS [11].

3. Blood pressure measurement was done as per the American heart association recommendations. Blood pressure was measured by clinical mercury sphygmomanometer in both the arms and the higher value was used for analysis ${ }^{[107]}$. Systolic Bp $>130$ and diastolic $\mathrm{BP}>85 \mathrm{~mm} \mathrm{Hg}$ or on specific treatment for this abnormality was taken as one of the criteria of MetS ${ }^{[11]}$. 
4 Blood sampling was done after the patients had been fasting for 12hours and following measurements were carried out:

A. A simple fasting capillary blood glucose level through a Roche Accu-Chek Inform ${ }^{\circledR}$ glucometer. It was ensured that the blood was flowing freely from a clean, warm, dry puncture site. First drop of blood was wiped away and the finger was squeezed slowly and rhythmically, gripping the digit firmly between the base of thumb and first finger. The patients with a fasting capillary glucose $>100 \mathrm{mg} / \mathrm{dL}$ were categorized as having impaired fasting glucose ${ }^{[11]}$. Studies have suggested that there is no significant difference between capillary whole blood and laboratory plasma.

Venous blood samples were taken to estimate
B. Triglyceride (TG) level; measured by PGO method (phosphoglyceroloxidase method). Triglyceride $>150 \mathrm{mg} / \mathrm{dl}$ or specific treatment for this lipid abnormality was taken as a criterion for MetS ${ }^{[11]}$.

C. High density lipoproteins cholesterol (HDL-C) level; measured by phosphortungstate method. HDL-C $<40 \mathrm{mg} / \mathrm{dl}$ for men and $<50 \mathrm{mg} / \mathrm{dl}$ for women or on specific treatment for both were taken as a criterion for MetS ${ }^{[11]}$

\section{Results}

Chi-square test was used to test the significance of difference in parameters of different groups. All $P$ values were two-tailed and statistical significance was defined as $P<0.05$. The results of the study are summarized in the tables (Table1, $2 \& 3$ ) and figure 1 below.

Table 1: Descriptive analysis of study group

\begin{tabular}{|c|c|c|}
\hline & Study Group & Metabolic syndrome Group \\
\hline No. Of Participants & 100 & $28(28 \%)$ \\
\hline Males & 67 & 19 \\
\hline Females & 33 & 2.11 \\
\hline M:F & 2.03 & 61.86 \\
\hline Mean Age (Years) & 60.92 & 62.26 \\
\hline Mean Age Males(Years)) & 62.85 & 61.0 \\
\hline Mean Age Females(Years) & 57.0 & 7.0 \\
\hline Duration of Symptoms (Years) & 6.69 & 7.63 \\
\hline Duration of symptoms Males(years) & 7.16 & 5.73 \\
\hline Duration of symptoms Females (years) & 5.67 & 22 \\
\hline Smokers & 76 & 288.2 \\
\hline Smoking Index & 143 & 364.7 \\
\hline Smoking index in males & 180 & 380 \\
\hline Smoking index in females & 67.88 & \\
\hline
\end{tabular}

Table 2: Various parameters of study group

\begin{tabular}{|c|c|c|c|}
\hline & Study Group & MetS Group & P value \\
\hline Waist Circumference $(\mathrm{cm})$ & 86.76 & 93.35 & $\mathrm{p}<0.001$ \\
\hline Waist circumference $(\mathrm{cm})$ Males & 89.46 & 95.26 & $\mathrm{p}<0.001$ \\
\hline Waist circumference $(\mathrm{cm})$ Females & 81.27 & 89.33 & $\mathrm{p}<0.001$ \\
\hline Mean FBS (mg \%) & 104.14 & 119.07 & $\mathrm{p}<0.001$ \\
\hline Mean FBS(mg\%)Males & 104.28 & 120.16 & $\mathrm{p}<0.001$ \\
\hline Mean FBS(mg\%)Females & 103.85 & 116.85 & $\mathrm{p}>0.001$ \\
\hline Mean TG (mg \%) & 137.29 & 153.89 & $\mathrm{p}<0.001$ \\
\hline Mean TG(mg\%)Males & 135.0 & 153.0 & $\mathrm{p}<0.001$ \\
\hline Mean TG(mg)F emales & 140.27 & 155.0 & $\mathrm{p}<0.001$ \\
\hline Mean HDL (mg \%) & 45.94 & 40.61 & $\mathrm{p}<0.001$ \\
\hline Mean HDL(mg)\% Males & 43.54 & 38.84 & $\mathrm{p}<0.001$ \\
\hline Mean HDL(mg)\%Females & 50.7 & 44.3 & $\mathrm{p}<0.001$ \\
\hline Mean Systolic BP (mm Hg) & 144.82 & 146.0 & $\mathrm{p}>0.001$ \\
\hline Mean Systolic BP (mm Hg)Males & 145.91 & 147.89 & $\mathrm{p}>0.001$ \\
\hline Mean Systolic BP(mm Hg)Females & 142.6 & 143.33 & $\mathrm{p}>0.001$ \\
\hline Mean Diastolic BP (mm Hg) & 87.48 & 89.14 & $\mathrm{p}>0.001$ \\
\hline \multicolumn{2}{|l|}{ Study Group } & \multicolumn{2}{|c|}{ MetS Group } \\
\hline Mean Diastolic BP (mmHg) Males & 86.86 & 87.47 & $\mathrm{p}>0.001$ \\
\hline Mean Diastolic BP (mmHg) Females & 88.73 & 92.67 & $p>0.001$ \\
\hline Mean Weight $(\mathrm{Kg})$ & 5.48 & 67.82 & $\mathrm{p}<0.001$ \\
\hline Mean Weight (Kg)Males & 55.18 & 67.79 & $\mathrm{p}<0.001$ \\
\hline Mean Weight $(\mathrm{Kg})$ Females & 53.06 & 67.89 & $\mathrm{p}<0.001$ \\
\hline Mean Height $(\mathrm{m})$ & 1.58 & 1.57 & $\mathrm{p}>0.001$ \\
\hline Mean Height(m)Males & 1.60 & 1.62 & $\mathrm{p}>0.001$ \\
\hline Mean Height $(\mathrm{m})$ Females & 1.53 & 1.51 & $\mathrm{p}>0.001$ \\
\hline Mean BMI & 21.7 & 27.30 & $\mathrm{p}<0.001$ \\
\hline Mean BMI Males & 21.32 & 26.10 & $\mathrm{p}<0.001$ \\
\hline Mean BMI Females & 22.6 & 29.96 & $\mathrm{p}<0.001$ \\
\hline At Risk & 0 & 0 & NIL \\
\hline Mild COPD & 7 & 0 & NIL \\
\hline Moderate COPD & 87 & 22 & \\
\hline Severe COPD & 6 & 6 & \\
\hline
\end{tabular}

The diagnosis of COPD was made in all patients based on spirometry and the severity of COPD was graded as per the Indian guidelines 
Table 3: Prevalence of MetS in different groups of COPD grades

\begin{tabular}{|c|c|c|c|}
\hline COPD GRADE (Indian Guidelines) & Frequency & Percent & No. of patients with MetS \\
\hline At risk & 0 & 0 & 0 \\
\hline Mild & 7 & 7 & 0 \\
\hline Moderate & 87 & 87 & 22 \\
\hline Severe & 6 & 6 & 6 \\
\hline Total & 100 & 100 & 28 \\
\hline
\end{tabular}

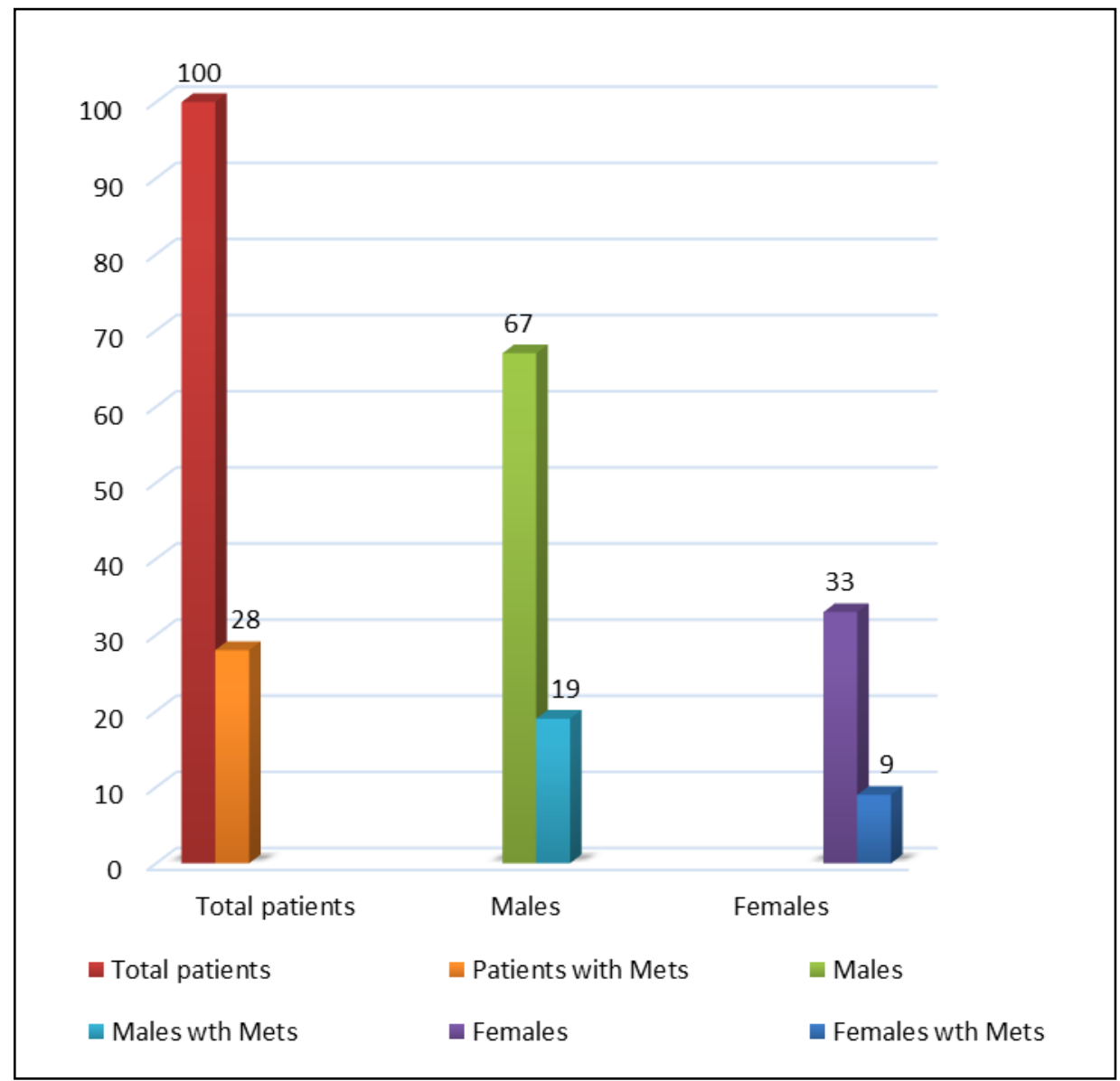

Fig 1: Prevalence of MetS

All the patients with severe COPD had MetS whereas none of the patients with mild COPD had MetS. Of all the patients included in the study, 28 patients with COPD had MetS as per the IDF guidelines giving the prevalence of MetS as $28 \%$. Of these 19 were males and 9 were females. Out of the 28 patients with MetS 22 were smokers (78.57\%) which is marginally higher than the percentage of the whole group. All patients with severe COPD had MetS. All the males with MetS were smokers whereas only 3 females with MetS gave a history of smoking. Raised fasting blood sugar was the most common metabolic abnormality in the patients with MetS.

\section{Discussion}

We present data on MetS in the COPD population not well described previously, with most of the present literature focusing on the general population in U.S. or Europe and very few in India.

Various definitions of MetS have been given, but we followed the definition given by International Diabetes Federation (IDF) consensus definition $2005^{\text {[1] }}$. In our study, although the mean age of patients with MetS (61.86 years) was marginally higher than that of those without it (60.56 years), the difference was not statistically significant.
The reports in the published literature suggest that the prevalence of MetS rises with age. The available literature shows that glucose handling may be impaired with age, mainly due to insulin resistance $[35,36]$. COPD further compounds this problem by the limitation of physical activity due to breathlessness forcing these patients to adopt sedentary life style. Kaur $\mathrm{P}$ et al. ${ }^{[37]}$. identified age more than 35 years as a risk factor for development of MetS. Numerous other studies show increasing incidence of MetS with increasing age ${ }^{[38,39,40]}$.

In the present study a greater number of patients with COPD were males and this trend was reflected in the male to female ratio of patients with MetS with a greater number of MetS patients being males (male to female ratio 2.1:1). COPD is a male dominant disease, the prevalence in males due to higher prevalence of smoking in this sex, and also males are more susceptible to smoking than females ${ }^{[41]}$. There was almost similar prevalence rate of MetS in males (28.4\%) and females $(27.3 \%)$ when the two groups were considered separately. This was higher than that reported by Kamble P et al. ${ }^{[42]}$ but they had used the ATP III criteria in their study. Ramachandran A et al. ${ }^{[38]}$ reported that MetS was more common in women $(46.5 \%)$ than in men $(36.4 \%)$ but they used the modified ATP III criteria in their study. 
The higher prevalence in females of certain groups may be a reflection of their different life style such as increased smoking among females or increased exposure to environmental tobacco smoke.

In our study there were $72 \%$ smokers in the whole group and $78 \%$ in MetS group. All the males with MetS were smokers whereas in the females with MetS only about $33 \%$ were smokers. Mean smoking index in the COPD patients with MetS (mean 288.1) was significantly higher than that in the COPD patients without it (86.53), $(\mathrm{P}<0.001)$. The smoking index was significantly higher in the male COPD patients with MetS (mean 364.74) than in the male COPD patients without it $(106.88),(\mathrm{P}<0.001)$. This finding favors the hypothesis that smoking may be associated with MetS independently. Among females, the difference between the two groups was not statistically significant. This may be explained by the low number of females with MetS (9\%) and among them still lower number of females with history of smoking (3\%). A number of authors have established a

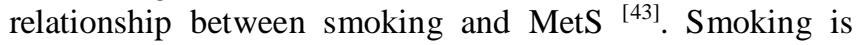
also regarded as an independent risk factor for MetS ${ }^{[44]}$. There are a number of studies showing that smoking is not only responsible for lung function impairment but can also lead to systemic inflammation thus contributing to systemic manifestation of COPD including MetS ${ }^{[29,45]}$.

Waist circumference (WC) is the essential criteria required for diagnosis of MetS as per the IDF guidelines. In our study $28 \%$ of the patients had WC more than the cut off for their sex. The difference between the mean WC of the patients with MetS $(93.36 \mathrm{~cm})$ and the patients without MetS $(86.53 \mathrm{~cm})$ was statistically significant $(\mathrm{p}<0.001)$. On individual comparisons the mean WC of males with MetS $(95.26 \mathrm{~cm})$ with the mean WC of males without MetS $(87.17 \mathrm{~cm})$ was statistically significant $(\mathrm{p}<0.001)$. The difference between mean WC of females with MetS (89.33 $\mathrm{cm})$ and the mean WC of females without MetS $(78.25 \mathrm{~cm})$ was statistically significant $(\mathrm{p}<0.001)$. This was similar to findings by $\mathrm{Kim} \mathrm{SH}$ et al. ${ }^{[46]}$. who reported that waist WC was significantly more in patients of COPD with MetS than in patients of COPD without MetS) $(\mathrm{p}<0.001)$. Leone $\mathrm{N}$ et al. ${ }^{[47]}$ reported that obesity was the strongest predictor of lung function impairment. Abdominal obesity (increased WC) may be one of the factors linking MetS and impaired lung function. This association may result from the mechanical effects of truncal obesity and/or the metabolic effects of adipose tissue ${ }^{[48,49,50]}$.

Impaired glucose metabolism (or presence of diabetes), which is also one of the criteria for the diagnosis of MetS, has been linked to impaired lung function ${ }^{[51]}$. In our study the mean fasting blood sugar(FBS) level of the COPD patients with MetS (116.78 $\mathrm{mg} \%)$ was significantly higher than that of patients without MetS (99 mg\%), ( $\mathrm{p}<0.001)$. The mean FBS level of the male COPD patients with MetS $(119.07 \mathrm{mg} \%)$ was significantly higher than that of male patients without MetS $(98.33 \mathrm{mg} \%)$, $(\mathrm{p}<0.001)$. The mean FBS level of the female COPD patients with MetS (116.78 $\mathrm{mg} \%)$, was significantly higher than that of female patients without MetS (99 mg\%), $(\mathrm{p}<0.001) .85 \%$ of the patients with MetS showed a raised FBS level. This was also the most common component of MetS identified in our study. Diabetes is often found to be comorbid with chronic obstructive pulmonary disease ${ }^{[52,53]}$. Engström G et al. ${ }^{[54]}$ reported that subjects with a moderately reduced FVC have an increased risk of developing insulin resistance and diabetes. Leone $\mathrm{N}$ et al. ${ }^{[47]}$ reported that lung function impairment was associated with MetS (prevalence $=15.0 \%$ ) independently of age, sex, smoking status, alcohol consumption, educational level, body mass index, leisuretime physical activity, and cardiovascular disease history. Kim SK et al. ${ }^{[55]}$ reported that fasting serum glucose was significantly higher in subjects in the lowest FVC quartile. Stratev V et al. ${ }^{[56]}$ also reported that fasting blood glucose in COPD subjects with the MetS was significantly higher compared to those without MetS $(\mathrm{p}<0.01)$.

Apart from being one of the components of the MetS raised triglyceride (TG) levels may be related with poor lung function also. In our study the mean serum TG level of the COPD patients with MetS (153.89 mg\%) was significantly higher than that of patients without MetS (130.83 $\mathrm{mg} \%$ ), $(\mathrm{p}<0.01)$. The mean serum TG level of male COPD patients with MetS (153.37 mg\%), was significantly higher than that of male patients without MetS $(128.88 \mathrm{mg} \%),(\mathrm{p}<0.01)$. The mean serum TG level of female COPD patients with MetS (155 $\mathrm{mg} \%$ ), was significantly higher than that of female patients without MetS(134.75 mg\%), (p<0.01). 64.3\% of the patients with MetS showed a raised TG level. This was the third most common component of MetS identified in our study. Ramachandran A et al. ${ }^{[38]}$ reported TG level was increased in $45.6 \%$. Gupta A et al. ${ }^{[57]}$ reported High TG levels were seen in $32.1 \%$ men and $28.6 \%$ women. Leone $\mathrm{N}$ et al. ${ }^{[47]}$ reported that high TG levels were inversely related to impaired lung function. Stratev $\mathrm{V}$ et al. ${ }^{[56]}$ also reported that TG were significantly higher in patients with MetS $(\mathrm{p}<0.01)$.

In our study the mean serum high density lipoprotein cholesterol (HDL-C) level of the COPD patients with MetS (40.61 mg\%), was significantly lower than that of patients without MetS $(45.94 \mathrm{mg} \%),(\mathrm{p}<0.001)$. The mean serum HDL-C level of male COPD patients with MetS (38.84 $\mathrm{mg} \%)$, was significantly lower than that of male patients without MetS (43.54 mg\%), $(\mathrm{p}<0.001)$. The mean serum HDL-C level of female COPD patients with MetS (44.33 $\mathrm{mg} \%$ ), was significantly lower than that of female patients without MetS (50.75 mg\%), $(p<0.001) .64 .3 \%$ of the patients with MetS showed a decreased HDL-C levels. This was the third most common component of MetS identified in our study along with raised TG levels. Ramachandran A et al. ${ }^{[38]}$ reported low HDL-C was seen in $65.5 \%$. Leone $\mathrm{N}$ et al. ${ }^{[47]}$ reported that low HDL-C levels were found to be inversely related to impaired lung function. Stratev $\mathrm{V}$ et al. ${ }^{[56]}$ also reported that in COPD subjects with the MetS HDL$\mathrm{C}$ levels were significantly lower compared to those without MetS ( $\mathrm{p}=0.017)$.

In our study, the mean systolic blood pressure(SBP) of the of the COPD patients with MetS(148.08 $\mathrm{mm} \mathrm{Hg}$ ), was marginally higher than that of patients without MetS $(146.43 \mathrm{~mm} \mathrm{Hg}),(\mathrm{p}>0.001)$. In the present study nearly $78 \%$ of the patients had hypertension which is higher than some of the reports. Leone $\mathrm{N}$ et al. ${ }^{[47]}$ reported that blood pressure was inversely related to lung function. Kim SK et al. ${ }^{[55]}$ reported that SBP, was significantly higher in subjects in the lowest FVC quartile as compared with those in the highest FVC quartile. Jové ORL et al. ${ }^{[58]}$ reported systemic hypertension in $48.2 \%$ of the subjects.

In our study, the mean weight of the of the COPD patients with MetS $(67.82 \mathrm{Kg})$, was significantly higher than that of patients without MetS $(54.85 \mathrm{Kg}),(\mathrm{p}<0.001)$. The mean weight of the of the male COPD patients with MetS (67.79 
$\mathrm{Kg}$ ), was significantly higher than that of male patients without MetS $(55.77 \mathrm{Kg}),(\mathrm{p}<0.001)$. The mean weight of the of the female COPD patients with MetS $(67.89 \mathrm{Kg})$, was significantly higher than that of female patients without MetS $(53 \mathrm{Kg}),(\mathrm{p}<0.001)$. The mean Body Mass Index (BMI) of the of the COPD patients with MetS $\left(27.4 \mathrm{Kg} / \mathrm{m}^{2}\right)$, was significantly higher than that of patients without MetS $\left(21.8 \mathrm{Kg} / \mathrm{m}^{2}\right),(\mathrm{p}<0.001)$. The mean BMI of the of the male COPD patients with MetS $\left(26.1 \mathrm{Kg} / \mathrm{m}^{2}\right)$, was significantly higher than that of male patients without MetS (21.4 $\left.\mathrm{Kg} / \mathrm{m}^{2}\right),(\mathrm{p}<0.001)$. The mean BMI of the of the female COPD patients with MetS $\left(29.9 \mathrm{Kg} / \mathrm{m}^{2}\right.$ ), was significantly higher than that of female patients without MetS (22.6 $\left.\mathrm{Kg} / \mathrm{m}^{2}\right),(\mathrm{p}<0.001)$. The difference between the heights of the two groups was not significant. There are a number of studies which establish a link between obesity, MetS and smoking ${ }^{[16,43,59]}$ Leone $\mathrm{N}$ et al. ${ }^{[47]}$ found that abdominal obesity was the strongest predictor of lung function impairment. Ervin RB ${ }^{[39]}$ reported that overweight males were about six times as likely and obese males were about 32 times as likely as normal weight males to meet the criteria for MetS. Overweight females were more than five times as likely and obese females were more than 17 times as likely as normal weight females to meet the criteria for MetS. Kamble P et al. ${ }^{[42]}$ reported that BMI of $23.32 \mathrm{~kg} / \mathrm{m} 2$ and higher was found to predict significant risk of MetS. Ortiz AP et al. ${ }^{[40]}$ observed a dose-response relationship between body mass index (BMI) and MetS. Stratev V et al. ${ }^{[56]}$ reported that in COPD subjects with the MetS, body mass index, was significantly higher compared to those without MetS $(\mathrm{p}<0.01)$.

In our study all the patients with severe COPD had the MetS and none of the patients with mild COPD had it. This is in contrast to some reports that conclude that MetS may be less prevalent in patients with more severe COPD which may be due to weight loss that occurs in advanced stages of the disease ${ }^{[60,61]}$. Jové ORL et al. ${ }^{[58]}$ \& Bulcun E et al. ${ }^{[62]}$ reported a higher rate of MetS in patients with stage II COPD than that in patients with stage IV COPD. In our study all the patients with severe COPD had hypertension, smoking index $>200$ and $\mathrm{WC}>94 \mathrm{~cm}$ for men and $>80 \mathrm{~cm}$ in women. This observation confirms the complex relationship that exists between MetS, obesity, FBS levels and COPD with each condition contributing to and modifying the natural history of the others.

In the present study prevalence of MetS was $28 \%$. In males it was $28.3 \%$ and in females it was $27.2 \%$. This was slightly lower than that reported by Watz ${ }^{[60]}$. Kaur $\mathrm{P}$ et al. ${ }^{[37]}$ reported the prevalence of the MetS as $41.3 \%$ and $51.4 \%$ using IDF and AHA/NHLBI criteria respectively. Kamble P et al. ${ }^{[42]}$ reported overall MetS as per ATP-III criteria was observed in 5.0 per cent adult rural population. When ATPIII criteria were modified using waist circumference cut-offs recommended by Asia-Pacific guidelines, MetS was seen in 9.3 per cent. It was 10.7 per cent among females and 8.2 per cent among males. Jové ORL ${ }^{[58]}$ reported MetS in $37.2 \%$ of COPD patients using IDF definition. Stratev V et al. ${ }^{[56]}$ reported that $41.8 \%$ of the COPD patients had MetS using IDF criteria. Thus, it's quite clear that the prevalence of MetS can change with the population under study and the definition of the syndrome being used.

Although each of the components of the MetS individually have been identified as risk factors for cardiovascular disease, an individual with three or more components is at particularly high risk. The results of our study and other studies discussed above clearly support the hypothesis that chronic obstructive pulmonary disease can no longer be considered a disease affecting the lungs alone. The available data indicates that:

1. There is an important systemic component associated with Chronic obstructive pulmonary disease

2. Clinical assessment and treatment of chronic obstructive pulmonary disease should also include the assessment of the systemic components of the disease; and their treatment as well.

A better understanding of the systemic effects of chronic obstructive pulmonary disease may permit new therapeutic strategies that might result in a better health status and prognosis for the patients

\section{Limitations of the study}

The low number of 28 cases of MetS in 100 cases of COPD is too small and hence large multicentric studies are required to establish the complex role of COPD in MetS and to establish whether while managing COPD treatment should also be aimed at the components of MetS to bring about a decrease in COPD related morbidity and mortality.

\section{References}

1. Haffner SM, Valdez RA, Hazuda HP, Mitchell BD, Morales PA, Stern MP. Prospective analysis of the insulin-resistance syndrome (syndrome X). Diabetes. 1992; 41:715-722.

2. Isomaa B, Almgren P, Tuomi T, Forsén B, Lahti K, Nissén $\mathrm{M}$ et al. Cardiovascular morbidity and mortality associated with the MetS. Diabetes Care. 2001; 24:683689.

3. Trevisan M, Liu J, Bahsas FB, Menotti A. Syndrome X and mortality: a population-based study. Risk Factor and Life Expectancy Research Group. Am J Epidemiol. 1998; 148:958-966.

4. Executive Summary of The Third Report of the National Cholesterol Education Program (NCEP) Expert Panel on Detection, Evaluation, and Treatment of High Blood Cholesterol In Adults (Adult Treatment Panel III). JAMA. 2001; 285:2486-2497.

5. DeFronzo RA, Ferrannant E. Insulin resistance a multifaceted syndrome responsible for NIDDM, obesity, hypertension, dyslipidemia, and atherosclerotic cardiovascular disease. Diabetes Care. 1991; 14:173194.

6. Descovich GC, Benassi B, Cancelli V, D' Addato S, De Simone, Dorrni A: AN epidemic view of the plurimetabolic syndrome. In Diabetes, Obesity and Hyperlipidemias. V. The Plurimetabolic Syndrome Crepaleli G, Tiengo A. Manzalo E, Eds. Amsterdam, Netherlands, Elsevier Science, 1993, 31-39.

7. Bouchard C, Perusse L. Genetics of causes and manifestations of the MetS in Diabetes obesity and hyperlipidemia: V. The plurimetabolic syndrome Crepaldi G. Tiengo A, Manzalo E, Eds. Amsterdam, Elsevier Science, 1993, 67-74.

8. Kaplan NM: The deadly quarter: upper body obesity, glucose intolerance, hypetriglyceridemia, and hypertension. Arch intern Med. 1989; 149:1514-1520.

9. Repine JE, Bast A, Lankhorst I. Oxidative stress in chronic obstructive pulmonary disease. Oxidative Stress 
Study Group, Am J respire Crit Care Med. 1997; 156:341-357.

10. MacNee W. Rahman L is oxidative stress central to the pathogenesis of chronic obstructive pulmonary disease? Trends Mol Med. 2001: 7:55-62.

11. Pi-Sunyer X. The MetS: How to Approach Differing Definitions. Med Clin N Am. 2007; 91:1025-1040.

12. Loper AD, Mathers CD, Ezzati M, Jamison DT, Murray Global regional burden of disease and risk factors, 2001, systematic analysis of population health data Lancet. 2006; 367:1747-1748.

13. Mannino DM, Watt G, Hole D et al. the natural history of chronic obstructive pulmonary disease. Eur Respir J. 2006; 27:627-643

14. Boyd CM, Darer J Boult, C Fried LT. Boult Wu AW Clinical practice guidelines and quality of care for older patients with multiple comotried disease implications for pay for performance JAMA. 2005; 294:716-724.

15. Rutten FH, Cramer MJ, Lammers JW, Grobbee DE, Hoes AW. Heart failure and chronic obstructive pulmonary disease: an ignored combination? Eur J Heart Fail. 2006; 8:706-711

16. Poulain M, Doucet M, Major GC et al. The effect of obesity on chronic respiratory diseases: pathophysiology and therapeutic strategies. CMAJ. 2006; 174:1293-1299

17. Marquis K, Maltais F, Duguay V, Bezeau AM, LeBlanc $\mathrm{P}$, Jobin J. The MetS in Patients With Chronic Obstructive Pulmonary Disease. Journal of Cardiopulmonary Rehabilitation. 2005; 25:226-232.

18. Walker CG, Zariwala MG, Holness MJ, Sudgen MC. Diet, obesity and diabetes: a current update. Clin Sci. 2007; 112:93-111.

19. Redelmeier DA, Tan SH, Booth GL. The treatment of unrelated disorders in patients with chronic medical diseases. N Engl J Med. 1998; 338:1516-1520.

20. Sin DD, Man SF. Why are patients with chronic obstructive pulmonary disease at increased risk of cardiovascular diseases? The potential role of systemic inflammation in chronic obstructive pulmonary disease. Circulation. 2003; 107:1514-1519.

21. Lange P, Nyboe J, Jensen G, Schnohr P, Appleyard M. Ventilatory function impairment and risk of cardiovascular death and of fatal or non-fatal myocardial infarction. Eur Respir J. 1991; 4:1080-1087.

22. Sparrow D, Weiss ST, Vokonas PS, Cupples LA, Ekerdt DJ, Colton T. Forced vital capacity and the risk of hypertension: The Normative Aging Study. Am J Epidemiol. 1988; 127:734-741.

23. Ford ES, Mannino DM. Prospective association between lung function and the incidence of diabetes: Findings from the National Health and Nutrition Examination Survey Epidemiologic Follow-up Study. Diabetes Care. 2004; 27:29662970.

24. Cirillo DJ, Agrawal Y, Cassano PA. Lipids and pulmonary function in the Third National Health and Nutrition Examination Survey. Am J Epidemiol. 2002; 155:842-848.

25. Bottai M, Pistelli F, Di Pede F, Carrozzi L, Baldacci S, Matteelli $\mathrm{G}$ et al. Longitudinal changes of body mass index, spirometry and diffusion in a general population. Eur Respir J. 2002; 20:665-673.

26. Zureik M, Kauffmann F, Touboul PJ, Courbon D, Ducimetiere P. Association between peak expiratory flow and the development of carotid atherosclerotic plaques. Arch Intern Med. 2001; 161:1669-1676.

27. Despres JP, Lemieux I, Bergeron J, Pibarot P, Mathieu $\mathrm{P}$, Larose $\mathrm{E}$ et al. Abdominal obesity and the MetS: contribution to global cardiometabolic risk. Arterioscler Thromb Vasc Biol. 2008; 28:1039-1049.

28. Barnes PJ, Celli BR. Systemic Manifestations and comorbidities of COPD. Eur Respir J. 2009; 33:11651185.

29. Vernooy JH, Kucukayan M, Jacobs JA, Chavannes NH, Buurman WA, Dentener MA. Local and systemic inflammation in patients with chronic obstructive pulmonary disease: soluble tumor necrosis factor receptors are increased in sputum. Am J Respir Crit Care Med. 2002; 166:1218-1224.

30. Takabatake N, Nakamura H, Abe S, Inoue S, Hino T, Saito $\mathrm{H}$. The relationship between chronic hypoxemia and activation of the tumor necrosis factor-alpha system in patients with chronic obstructive pulmonary disease. Am J Respir Crit Care Med. 2000; 161:1179-1184.

31. Skeletal muscle dysfunction in chronic obstructive pulmonary disease. American Thoracic Society, European Respiratory Society. Am J Respir Crit Care Med. 1999; 159:S1-40.

32. Couillard A, Maltais F, Saey D, Debigare R, Michaud A, Koechlin C. Exercise-induced quadriceps oxidative stress and peripheral muscle dysfunction in patients with chronic obstructive pulmonary disease. Am J Respir Crit Care Med. 2003; 167:1664-1669.

33. Koechlin C, Couillard A, Cristol JP, Chanez P, Hayot M, Le GD. Does systemic inflammation trigger local exercise-induced oxidative stress in COPD? Eur Respir J. 2004; 23:538-544.

34. Arora VK. Guidelines For Management Of COPD In India: A Guide for Physicians 2003. In: Arora VK, editor. Practical Approach To Respiratory Diseases. New Delhi: Jaypee Brothers Medical Publishers, 2005, 497.

35. Ferrannini E, Vichi S, Beck-Nielsen $\mathrm{H}$ et al. Insulin action and age. European Group for the Study of Insulin Resistance (EGIR). Diabetes. 1996; 45(7):947-53.

36. Barbieri M, Rizzo MR, Manzella D et al. Age-related insulin resistance: is it an obligatory finding? The lesson from healthy centenarians. Diabetes Metab Res Rev. 2001; 17(1):19-26.

37. Kaur P, Radhakrishnan E, Rao SR, Sankarasubbaiyan S, Rao TV, Mohan Digamber Gupte. The MetS and Associated Risk Factors in an Urban Industrial Male Population in South India. Journal of the Association of Physicians of India. 2010; 58:363-366.

38. Ramachandran A, Snehalatha C, Satyavani K, Sivasankari S, Vijay V. MetS in urban Asian Indian adults-a population study using modified ATP III criteria. Diabetes Res Clin Pract. 2003; 60(3):199-204.

39. Ervin RB. Prevalence of MetS among Adults 20 Years of Age and Over, by Sex, Age, Race and Ethnicity, and Body Mass Index: United States, 2003-2006 National Health Statistics Reports. 2009; 13:1-7.

40. Ortiz AP, Suárez E, Beauchamp G, Romaguera J, SotoSalgado M, Pérez CM. Correlates of the MetS Among a Sample of Women in the San Juan Metropolitan Area of Puerto Rico. MetS and Related Disorders. 2010; 8(3):235-242.

41. Postma Dirkje S. Kerstjens AM Huib. Epidemiology 
and natural history of chronic obstructive pulmonary disease. In: Gibson G John, Geddes M Duncan, Costabel Ulrich, Sterk J Peter, Corrin Bryan, editors. Respiratory Medicine. 3rd ed. Saunders. 2003; 2:110920.

42. Kamble P, Deshmukh PR, Garg N. MetS in adult population of rural Wardha, central India. Indian J Med Res. 2010; 132(6):701-705.

43. Oh SW, Yoon Ys, Lee ES, Kim Wk, Park Cy, Lee S. Association Between Cigarette Smoking and MetS (The Korea National Health and Nutrition Examination Survey). Diabetes Care. 2005; 28(8):2064-2066.

44. Takeuchi T, Nakao M, Nomura K, Yano E. Association of MetS with smoking and alcohol intake in Japanese men. Nicotine Tob Res. 2009; 11:1093-1098.

45. Fabbri LM, Luppi F, Beghe B, Rabe KF. Complex chronic comorbidities of COPD Eur Respir J. 2008; 31:204-212.

46. Kim SH, Lee N, Lee SN, Lee WY, Yong SJ, Shin KC. Risk factors of MetS in male patients with chronic obstructive pulmonary disease. Chest; 2009(10): 136(4_MeetingAbstracts):118S-c-119S

47. Leone N, Courbon D, Thomas F, Bean K, Je'go, Leynaert B. Lung Function Impairment and MetS The Critical Role of Abdominal Obesity. American Journal Of Respiratory And Critical Care Medicine. 2009; 179:509-516

48. McClean KM, Kee F, Young IS, Elborn JS. Obesity and the lung: 1.Epidemiology. Thorax. 2008; 63:649654.

49. Sutherland TJ, Goulding A, Grant AM, Cowan JO, Williamson A, Williams SM. The effect of adiposity measured by dual-energy X-ray absorptiometry on lung function. Eur Respir J. 2008; 32:85-91.

50. Franssen FM, O’Donnell DE, Goossens GH, Blaak EE, Schols AM. Obesity and the lung: 5. Obesity and COPD. Thorax. 2008; 63:1110-1117.

51. Ford ES, Mannino DM. Prospective association between lung function and the incidence of diabetes: findings from the National Health and Nutrition Examination Survey Epidemiologic Follow-up Study. Diabetes Care. 2004; 27(12):2966-70.

52. Mannino DM, Thorn D, Swensen A, Holguin F. Prevalence and outcomes of diabetes, hypertension and cardiovascular disease in COPD. Eur Respir J. 2008; 32:962-969.

53. Yeh HC, Punjabi NM, Wang NY, Pankow JS, Duncan $\mathrm{BB}$, Cox CE. Cross-sectional and prospective study of lung function in adults with type 2 diabetes: the Atherosclerosis Risk in Communities (ARIC) study. Diabetes Care. 2008; 31:741-746.

54. Engström G, Hedblad B, Nilsson P, Wollmer P, Berglund G, Janzon L. Lung function, insulin resistance and incidence of cardiovascular disease: a longitudinal cohort study. J Intern Med. 2003; 253(5):574-581.

55. Kim SK, Hur KY, Choi YH, Kim SW, Chung JH, Kim HK. The relationship between lung function and MetS in obese and non-obese Korean adult males. Korean Diabetes J. 2010; 34(4):253-260.

56. Stratev V, Petev J, Galcheva S, Peneva M. The MetS (MetS) in patients with chronic obstructive pulmonary disease (COPD) and its association with airway obstruction. presented at ERS Annual Congress Vienna, 2012.
57. Gupta A, Gupta R, Sarna M, Rastogi S, Gupta VP, Kothari K. Prevalence of diabetes, impaired fasting glucose and insulin resistance syndrome in an urban Indian population. Diab Res Clin Pract. 2003; 61(1):6976.

58. Jové ORL, González EL, Rey S, Giugno E, Barrionuevo V, Galdames A. Evaluation of association between COPD and MetS, and insulin resistance. presented at ERS Annual Congress - Vienna, 2012.

59. Björntorp P. Abdonimal obesity and the MetS. Ann Med. 1992; 24(6):465-468.

60. Watz H, Waschki B, Kirsten A, Müller KC, Kretschmar G, Meyer T. The MetS in Patients With Chronic Bronchitis and COPD. Chest. 2009; 136 (4):1039-1046

61. Minas M, Kostikas K, Papaioannou AI, Mystridou P, Karetsi E, Georgoulias P. The association of MetS with adipose tissue hormones and insulin resistance in patients with COPD without co-morbidities. COPD. 2011; 8(6):414-420.

62. Bulcun E, Ekici A, Ekic M. MetS and chronic diseases in COPD presented at ERS Annual Congress - Vienna, 2012. 